\title{
Effect of Transverse Compression on Web-crushing Strength of Reinforced Concrete I-shaped Beams
}

\author{
V.P. Pochinok, E.V. Greshkina, M.A. Tamov, M.M. Tamov \\ Institute of Construction and Transport Infrastructure \\ Kuban State Technological University \\ Krasnodar, Russian Federation \\ murat.tamov@gmail.com
}

\begin{abstract}
The paper presents results of theoretical research of effect of transverse compression in a shear span zone on webcrushing strength of I-shaped reinforced concrete beams. The hypothesis of an increase of web shear strength in case of clamping by prestressed external strengthening transversal reinforcement was checked. The principal variable was the level of clamping stresses which was taken to be up to half of compressive strength of concrete. A shear span and a shear reinforcement ratio were also varied. Shear strength of I-shaped reinforced concrete beams was calculated using nonlinear rational model CSMM implemented in finite elements framework software OpenSees. Validity of the model for estimation of the shear strength gain due to transverse compression was proved by close prediction of results in similar analyses of I-shaped reinforced concrete beams. Fulfilled modeling demonstrated the increase of web-shear strength as a result of external shear strengthening. This effect is observed to a greater degree in cases of loadings with large shear spans. The largest increase of shear strength takes place in beams with transverse stresses in a range of $20-40 \%$ of compressive strength of concrete decreasing with further growth of the clamping stresses level. The found effect and accuracy of its estimation need to be verified by special experimental research.
\end{abstract}

Keywords-web-crushing strength; external shear strengthening; transverse stresses; reinforced concrete I-beams; shear force.

\section{INTRODUCTION}

Shear strength of reinforced concrete I-beams is governed by the plain stress state of the web, which is a membrane element with uniformly distributed vertical reinforcement fixed in relatively rigid flanges. Over the last 50 years, a lot of special experimental studies were focused on the issue of the concrete crushing strength of the web. In some cases this mode of failure took place in full-scale tests of I-shaped bridge girders in Russia, Germany, the United States and other countries.

Results of these tests demonstrate that web-crushing strength of beams depends not only on concrete strength and dimensions of cross-sections, but also to a variable extent on many other factors: reinforcement ratio of the web, moment to shear force ratio $M / V$, prestressing of the reinforcement, axial forces in the cross-section due to loading and their eccentricities, presence of inclined cracks formed under previous loadings, etc.
Almost all Russian studies of web-crushing strength of beams suggest empirical formulas that take into account the found impact of a certain factor. Russian building codes SP 63.13330.2012 "Concrete and Reinforced Concrete Structures" and SP 35.13330.2011 "Bridges and Culverts" also use empirical formulas for the design value of shear force which can be sustained by the compression struts.

The SP 35.13330.2011 formula captures the effect of vertical and inclined reinforcement on the web-crushing strength of the beam. It also includes factor $\varphi_{b 1}$ that gives an approximate allowance for another important phenomenon relative reduction of the plane stress strength criterion for the high-strength concrete.

The formula of SP 63.13330.2012 does not account for the effect of shear reinforcement on the web strength. As a matter of fact, the formula of this code, $Q \leq 0.3 \varphi_{w 1} \varphi_{b 1} f^{\prime}{ }_{c} b_{w} h_{0}$, with $\varphi_{b 1}=0.3$ is similar to the conservative formula, $Q \leq 0.25 f^{\prime}{ }_{c} b_{w} h_{0}$, proposed by M.S. Borishanskiy in the middle of the past century as a result of his very first study which included tests of four couples of beams [1]. Difference in the values of overall factors in the formula of current code and that of M.S. Borishanskiy is due to the changes of principles in the setting of concrete strength characteristics and reduction of the standard specimens for strength determination in the mid1970s.

Thus, the current version of the code SP 63.13330 neglects all the obtained data of the numerous experimental studies although the previous version of the this code as well as current code for the design of bridges SP 35.13330.2011 took into account the effect of a reduction of the plane stress strength criterion and a shear reinforcement ratio on the webcrushing strength. This simplified approach of SP 63.13330 does not allow for reasonable correction of the geometrical parameters and detailing of the reinforced concrete I-shaped beams at the stage of design, neither does it suggest a way for analysis of the existing structures in case of changing the loading scheme. In particular, the issue of the design of strengthening the web of beams under increasing loads remains open.

Effect of transverse compressive stresses on the webcrushing strength of beams has not been deeply studied so far. Meanwhile it is established that prestressed external transversal reinforcement (Fig. 1) increases the shear compression capacity of beams. Such type of strengthening 
has long ago become classic. However its effectiveness in strengthening of the web of box-, T- and I-shaped beams which can fail due to crushing of concrete struts yet has not been subject of inquiry. Some researchers point out the slow growth of web strength with an increase of the shear reinforcement ratio in beams with unbonded stirrups. It is also unclear whether there is a limit value for the shear reinforcement ratio, above which additional strengthening stirrups become ineffective because of the partial utilization of their strength in case of failure due to web crushing.


Fig. 1. Principal schemes of strengthening beams by external transverse reinforcement

As it applies to I-shaped beams, strengthened with prestressed stirrups web-crushing strength alongside with aforementioned factors, it is also affected by detailing parameters of strengthening and the level of prestress of external transversal reinforcement. In order to test the assumption of increasing of web-crushing strength with strengthening by external stirrups, a preliminary experimental research was fulfilled at Kuban State Technological University [2]. In the first part of this research, the shear behavior of I-shaped beams was studied with stirrups unbonded by placing them in polyvinyl chloride pipes before beam casting. The second part included testing of the beams with bonded stirrups and strengthening with prestressed external stirrups, set vertically and at $45^{\circ}$ with respect to the longitudinal axis of the beam. Additionally, reference beams without strengthening and shear reinforcement were tested. The beams were loaded by a four-point bending scheme with shear span $a=65 \mathrm{~cm}(2.3 \mathrm{~h})$. Beams had section height $h=28$ $\mathrm{cm}$, thickness $b_{w}$ and height $h_{w}$ of the web and were accordingly equal to 3 and $19 \mathrm{~cm}$. The varied parameters included compressive strength of concrete $R=20-40 \mathrm{MPa}$, shear reinforcement ratio $\mu_{\mathrm{sw}}=0.0026-0.0175$, external shear reinforcement ratio $\mu_{\text {swstr }}=0.005-0.0125$. A minor initial tension equal to $1 \mathrm{kN}$ was created in stirrups to bring them into action at low loads. Results of the tests showed that the formula of the current Russian code overestimated webcrushing strength of the beams by 10-35\% if the external stirrups were considered as regular internal ones. In the meantime, strengthening of the web with extra transversal reinforcement increases its strength in cases of the low internal shear reinforcement ratio. The same strengthening proved ineffective in cases of high shear reinforcement ratios $\mu_{\mathrm{sw}}>$ $0.015 \ldots 0.02$ where stirrups are not utilized completely by the moment of crushing of the compression struts. Furthermore, strengthening with external inclined reinforcement was not found to be more advantageous than with a vertical one, although inclined internal stirrups are known to be much more effective in increasing web-crushing strength as compared to vertical stirrups.
So far it is not clear whether there is an optimum level for the clamping stresses of web for increasing its strength. Considering the results of the preliminary tests, there seems to be a need for further study of the effect of external prestressed transversal reinforcement on the web-crushing strength of reinforced concrete beams. Such study should aim at optimization of the level of web clamping stresses and at development of the method for analysis of this type of strengthening.

\section{FINITE ELEMENT MODELLING OF BEAMS}

Theory of shear is considered to be one of the most complex issues in the field of reinforced concrete. Professor Zalesov who was one of the developers of shear provisions in Russian building codes noted that semi-empirical formulas for shear adopted in building codes were not cross-functional and efficient due to wide range of types of reinforced concrete structures [3]. He also pointed out that existing methods adopted various models, imposed different restrictions and empirical equations obtained directly from tests. It particularly concerns design methods for shear and torsion. It was also noted that numerous attempts of developing more versatile methods have not yet yielded the desired result [4]. To improve the quality of design, it is necessary to develop computer methods of analysis verified by the relevant experimental research. The most promising in this respect are numerical analyses based on the finite elements method (FEM), which allows taking into account nonlinear mechanical properties of materials. Nonlinear analysis of reinforced concrete can be successfully accomplished in multipurpose or special FEM computer programs.

Considerable advancement in the subject of shear was made with the development of softened truss models (MCFT [5], RA-STM [6], FA-STM [7], CSMM [8, 9], etc.) which recognize cracked reinforced concrete as a new material that has its own stress-strain characteristics. These models satisfy the three fundamental principles of the mechanics of materials: stress equilibrium, strain compatibility and the constitutive laws of materials. One of the crucial benefits of softened truss models over discrete models is that former can be effectively incorporated in finite element simulation. Laskar [10] used program OpenSees to simulate shear behavior of full-scale prestressed concrete beams subjected to four-point bending. In our work [11], a similar approach was adopted for analysis of reinforced concrete I-shaped beams under two-stage loading with changing the shear span. OpenSees [12] has been developed as the computational platform for research in performance-based earthquake engineering at the Pacific Earthquake Engineering Research Center. It is an object-oriented software framework for simulation applications using the finite element method. It is comprised of a set of modules to perform creation of the finite element model, specification of an analysis procedure, selection of quantities to be monitored during the analysis and the output of results.

In nonlinear simulations, the web of the beams is modelled with quadrilateral elements with an assigned material class RCPlaneStress. Performance of this class is based on a Cyclic Softened Membrane Model (CSMM) - a fixed-angle model 
for reinforced concrete membrane elements subjected to cyclic in-plane loadings $[13,14]$. The cyclic uniaxial constitutive relationships of cracked concrete in compression and tension are defined by concrete model ConcreteZ01 [15, 16]. In steel model SteelZ01, cyclic stress-strain relationships are represented by a set of straight line segments and take into account the Bauschinger effect. Both the envelope and the unloading/reloading patterns for models ConcreteZ01 and SteelZ01 are illustrated in Fig. 2 and 3.

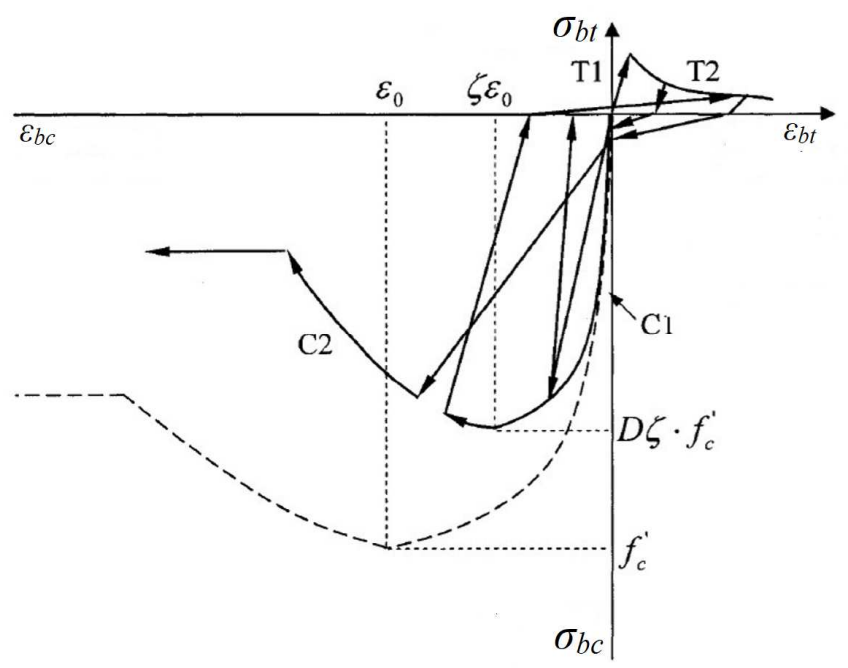

Fig. 2. A concreteZ01 material module [16].

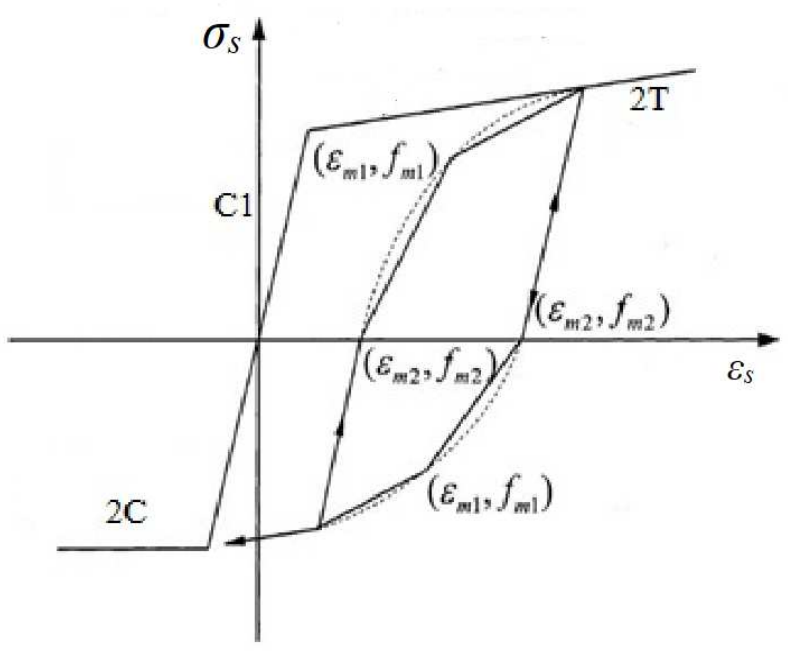

Fig. 3. A steelZ01 material module [16].

The effect of FE mesh size on the results of shear analyses of reinforced concrete elements with smeared models was studied by several researchers [10, 11, 16, etc.]. Finite elements with assigned CSMM properties are recognized as a continuum containing cracked concrete with embedded steel bars. Therefore reducing the size of the mesh does not always lead to more accurate results. One of our previous works [11] gives justification of the choice of the mesh size for quadrilateral isoparametric elements leading to the best correlation between results of analysis and tests. These recommendations conform with suggestion of other studies $[10,16]$.

In order to reveal the effect of transverse compression on the web-crushing strength, balanced load was applied to the flanges of the beam within shear span providing stresses $\sigma_{y}$ in the transverse direction with values in the range of $(0.1-0.5)$ $f_{c}^{\prime}$ (Fig. 4, 5). Clamping stresses were imposed with a load control integrator. External load $P$ was applied with a displacement control integrator allowing for various numbers and values of increment as well as obtaining the descending part of analytical load-displacement diagram.

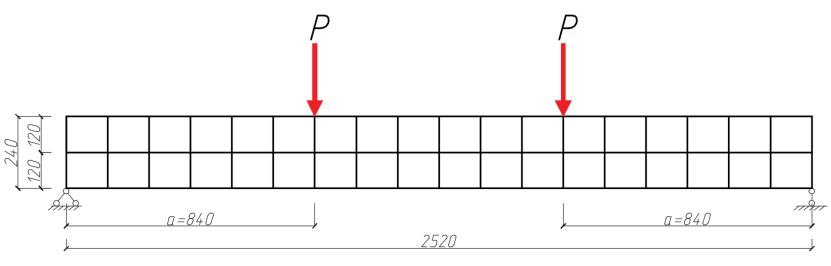

Fig. 4. A reference FE model of the beam

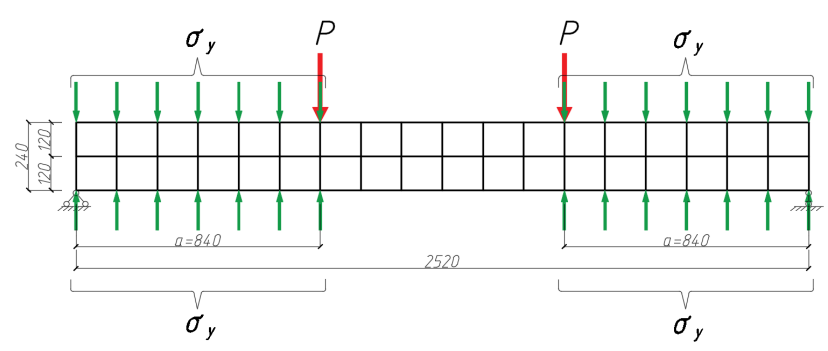

Fig. 5. An FE model of the beam with applied clamping stresses.

\section{RESULTS AND DISCUSSION}

The sensitivity of employed FE model to the positive effect of external compressive forces was verified by simulation of I-shaped reinforced concrete beams from tests of Abdullaev [17]. In these tests, it was established that the effect of axial compressive force on web-crushing strength depends on the level of resulting compressive stresses and eccentricity of axial force. Web-crushing strength increased with the growth of axial compressive stress to $(0.3-0.4) f_{c}{ }_{c}$. Further growth of imposed axial compression results in lower webcrushing capacity. Axial compression was effective only if the force was applied with eccentricity towards the tension zone. If the eccentricity was towards a compression zone, webcrushing strength decreased in all cases. Under an optimum level of axial compression, web-crushing strength increased by up to $25-30 \%$ with eccentricity $0.375 h_{0}$ and by up to $15 \%$ with eccentricity $0.19 h_{0}$. In the tests with the axial compressive force applied at the centroid of the section, no change in strength of the web was found. 
In Russian code SP 63.13330.2012, factor $\varphi_{n}$ accounting for positive effect of the axial compression level is calculated with formulas similar to the ones adopted in Eurocode [18]. In both codes, the maximum value of $\varphi_{n}$ is 1.25 with a level of axial compression equal to $0.25 f^{\prime}{ }_{c}$. However with a higher level of axial compression, provisions of Eurocode are more conservative: a reduction of $\varphi_{n}$ in Eurocode and SP 63.13330.2012 begins at the compression level of $0.5 f^{\prime}{ }_{c}$ and $0.75 f^{\prime}{ }_{c}$ respectively. These provisions of the codes do not fully comply with the results of special experimental research [17] with Eurocode giving more accurate results than SP 63.13330.2012.

Fig. 6 shows the results of analysis fulfilled with the aforementioned FE model for the beams of Abdullaev [17] having a varying level of axial compression.

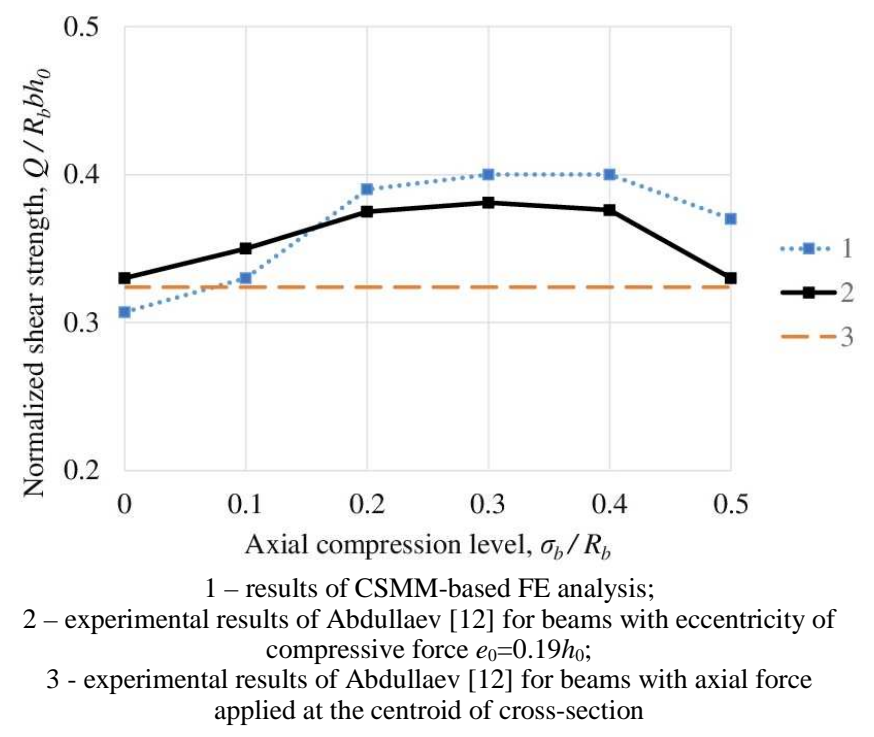

Fig. 6. Effect of axial compressive force on normalized shear strength of beams with shear reinforcement ratio $\mu_{\mathrm{sw}}=0,0148$

It can be seen that CSMM-based FE simulation in OpenSees provides generally correct predictions of webcrushing strength growth up to 25-30 \% under axial compression level $(0.3-0.4) f^{\prime}{ }_{c}$ and a further decrease with raising of compression stress. Therefore with a high degree of certainty we can assume that the model will as well provide correct estimation of the effect of transverse compression on the strength of the web. Beams No. 9 and No. 25 from the experimental research of Tamov [11] were taken as samples for such analysis. These beams were tested with shear span ratio $a / h_{0}=1.6$ and 3.2 and failed due to crushing of the web at the load of $Q=88.69$ and $61.94 \mathrm{kN}$ respectively. A shear reinforcement ratio in both cases was $\mu_{s w}=0.0059$ and compressive strength of concrete was $f_{c}^{\prime}=31.9 \mathrm{MPa}$. Examples of analytical load-displacement curves for these beams with levels of transverse stress $0.1 f^{\prime}{ }_{c}$ and $0.3 f^{\prime}{ }_{c}$ are illustrated in Fig. 7. Results show that clamping increases the strength of the web with a relatively low shear reinforcement ratio to a larger degree in case of large shear span $a / h_{0}=3.2$. With smaller shear span $a / h_{0}=1.6$, the gain in web-shear strength is less.
Similar analyses have been performed for beams No. 28 and No. 30 from our work [11] with three-time larger shear reinforcement ratio $\mu_{s w}=0.0164$, compressive strength of concrete $f^{\prime}{ }_{c}=30.8 \mathrm{MPa}$ and $33.0 \mathrm{MPa}$ and shear span ratio $a / h_{0}=1.6$ and 2.5 .

Fig. 8 shows a relationship between strength of the web and the level of transverse stress $\sigma_{y} / f_{c}^{\prime}$. The largest increase of the web-crushing strength is observed when the clamping stresses are equal to $20-40 \%$ of compressive strength of concrete $f^{\prime}{ }_{c}$. In beams with low shear reinforcement ratio $\mu_{\mathrm{sw}}=0.0059$, the peak of shear capacity shifted towards lower stress levels $0.3 f^{\prime}{ }_{c}$.

a)

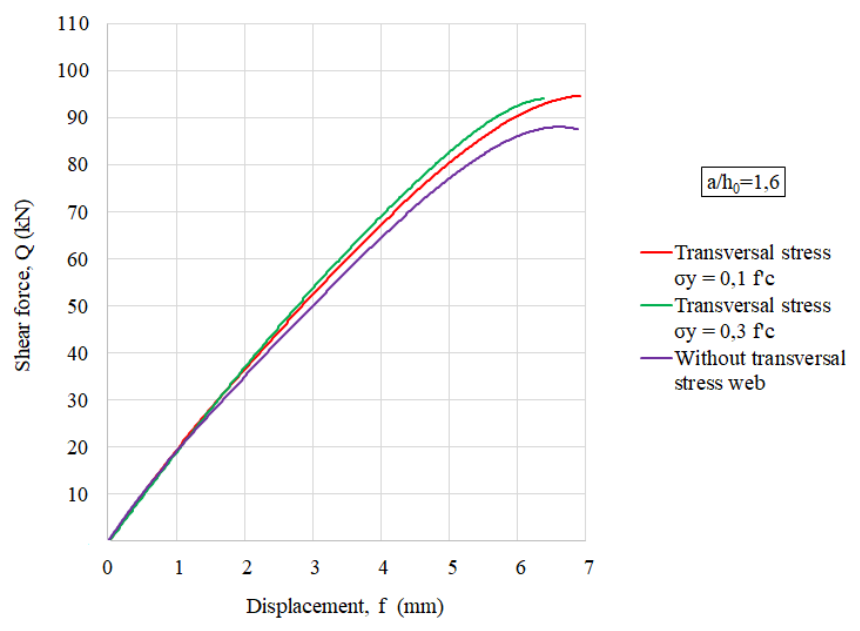

b)

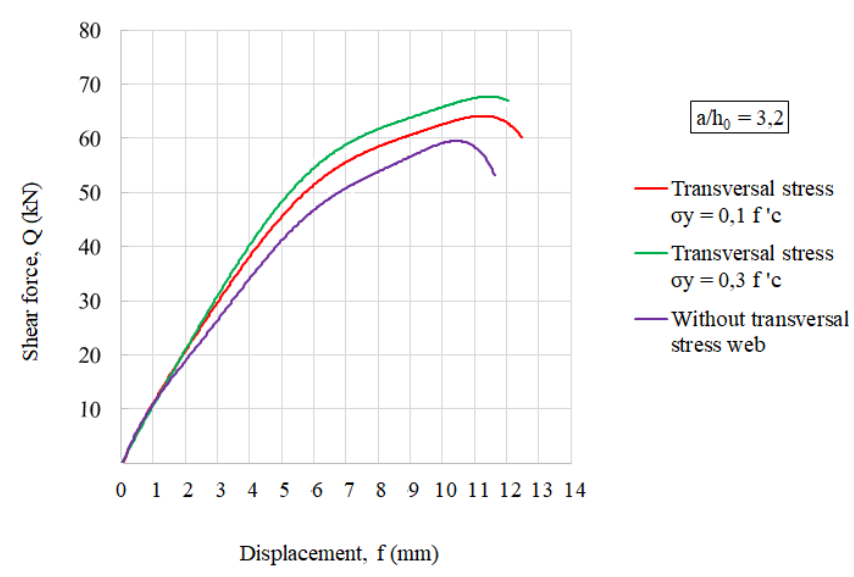

Fig. 7. Analytical load-displacement curves for the model of the I-shaped beams with $\mu_{\mathrm{sw}}=0.0059$ from the experimental research of M.M. Tamov [11]: a) beam No. 9 , shear $\operatorname{span} a=1,6 h_{0} ;$ b) beam No. 25, the span of shear $a=$ $3,2 h_{0}$

Transverse compression of the web increases its strength by $10-15 \%$, which is somewhat lower than in case of axial compression with eccentricity towards the tension zone, but higher than in case of action of the axial force in the centroid of the section. However, the found positive effect of transverse 
compression of the web in certain cases may provide a source for strengthening of the beams.

The results of fulfilled theoretical prediction should be verified by experiments.

a)

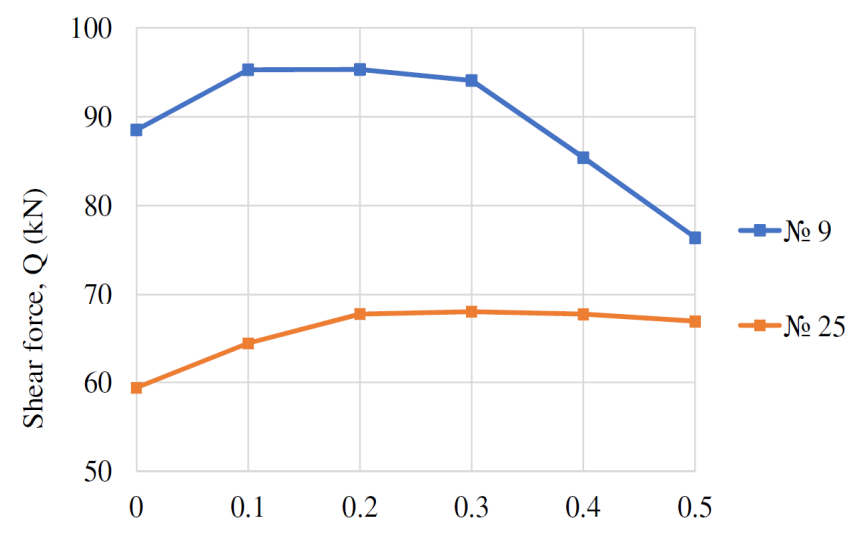

Axial compression, $\sigma_{\mathrm{y}} / \mathrm{f}^{\prime}{ }_{\mathrm{c}}$

b)



Fig. 8. Effect of transevrse compressive stresses $\sigma_{y} / f^{\prime} c$ on the web-crushing strength of beams with shear $\mu_{\mathrm{sw}}=0.0164$ : a) I-shaped beam No. 30, shear span $a=2.5 h_{0} ;$ b) I-shaped beam No. 28 , shear span $a=3.2 h_{0}$

\section{CONCLUSION}

1. Cyclic Softened Membrane Model (CSMM) integrated in framework software OpenSees is recommended for nonlinear finite element analysis of webs of I-shaped reinforced concrete beams. This model is capable of taking into account the known effect of the following factors on the web-crushing strength of beams: the size of the cross-section, mechanical properties of concrete, detailing of reinforcement, axial compression, loading schemes, etc.
2. Computer simulations show the increase of strength of the web with external clamping which can be fulfilled by prestressed transverse reinforcement. This effect is observed to a greater degree in beams loaded with larger shear spans.

3. The largest increment of web-crushing strength corresponds to the level of transverse compressive stresses $\sigma_{y}$ in the range of $20-40 \%$ of the compressive strength of concrete and decreases with further growth of clamping. This found effect and accuracy of its estimation is planned to be verified by special experimental research.

4. Validity of the CSMM-based FE model for estimation of the positive effect of transverse compression of the web was verified by close predictions of shear capacities in similar tests of I-shaped beams.

\section{References}

[1] M.S. Borishanskiy, "Novyye dannyye o soprotivlenii izgibayemykh elementov deystvitel'nykh poperechnykh sil" [New data on shear resistance structural elements subjected to bending] Moscow: Stroyizdat, 1952, pp. 136-152.

[2] V.P. Pochinok and R.G. Baloyan, "Raschet usileniya priopornykh uchastkov zhelezobetonnykh balok s tonkoy stenkoy" [Design of shear strengthening of reinforced concrete beams with thin web] Proc. II N.A. Conf. on Seism. Constr. and Seism. Zoning, pp. 81-82, September 1997, Sochi.

[3] A.S. Zalesov, "Kratkiye zametki o raschete zhelezobetonnykh konstruktsiy na deystviye poperechnykh sil" [Notes on shear analysis of reinforced concrete structures] Moscow: TsPP, 2008.

[4] A.S. Zalesov, "Kratkiye zametki o raschete zhelezobetonnykh konstruktsiy metodom konechnykh elementov" [Notes on finite elements analysis of reinforced concrete structures] Moscow: TsPP, 2008.

[5] F.J. Vecchio and M.P. Collins, "The modified compression field theory for reinforced concrete elements subjected to shear", ACI J., vol. 83, pp. 219-231, 1986.

[6] T.T.C. Hsu, "Softened truss model theory for shear and torsion", ACI Struct. J., vol. 85, pp. 624-635, 1988.

[7] X.B. Pang and T.T.C. Hsu, "Fixed angle softened truss model for reinforced concrete", ACI Struct. J., vol. 93, pp. 197-207, 1996.

[8] M. Mansour and T.T.C. Hsu, "Behavior of reinforced concrete elements under cyclic shear: part 1 - experiments", J. Struct. Eng., vol. 131, pp. 44-53, 2005.

[9] M. Mansour and T.T.C. Hsu, "Behavior of reinforced concrete elements under cyclic shear: part 2 - theoretical model", J. Struct. Eng., vol. 131, pp. 54-65, 2005.

[10] A. Laskar, Shear Behavior and Design of Prestressed Concrete Members. PhD thesis. TX: The University of Houston, 2009.

[11] M.M. Tamov, “ Nelineynoye komp'yuternoye modelirovaniye raboty dvutavrovykh zhelezobetonnykh balok na poperechnuyu silu" [Nonlinear computer simulation of shear behaviour of I-shaped reinforced concrete beams], Beton i Zhelezobeton, vol. 4, pp. 3-6, 2012.

[12] The Open System for Earthquake Engineering Simulation. URL: http://opensees.berkeley.edu/ OpenSees/home/about.php.

[13] T.T.C. Hsu and R.R.H. Zhu, "Softened Membrane Model for Reinforced Concrete Elements in Shear", Struct. J. of ACI, vol. 99, pp. 460-469, 2002.

[14] J.-Y. Lee, S.-W. Kim and M.Y. Mansour "Nonlinear Analysis of ShearCritical Reinforced Concrete Beams Using Fixed Angle Theory", J. Struct. Eng., vol. 137, pp. 1017-1029, 2011.

[15] Y.L. Mo, J. Zhong and T.T.C. Hsu, "Seismic simulation of RC wall-type structures", Eng. Struct., vol. 30, pp. 3167-3175, 2008. 
[16] J. Zhong, Model-based simulation of reinforced concrete plane stress structures. PhD thesis. TX: The University of Houston, 2005.

[17] A.R. Abdullaev, G.S. Aliev and M.M. Batdalov, "Issledovaniye vliyaniya prodol'nogo obzhatiya na prochnost' stenki dvutavrovykh zhelezobetonnykh elementov pri deystvii poperechnykh sil" [Investigation of the effect of axial compressive force on web-crushing strength of I-shaped reinforced concrete beams], Izvestiya vuzov. Severo-Kavkazskiy region. Tekhnicheskiye nauki, vol. 2, pp. 87-89, 2007.

[18] EN 1992-1-1:2004 (E) Eurocode 2: Design of concrete structures - Part 1-1: General rules and rules for buildings. 